\title{
Estimativa do benefício econômico potencial de dois levantamentos de solos no Estado do Rio Grande do Sul
}

\author{
Estimate of the potential economic benefit of two soil surveys in Rio Grande do Sul State, Brazil
}

\author{
Elvio Giasson $^{1,2}$ Alberto Vasconcellos Inda Junior ${ }^{1}$ Paulo César do Nascimento $^{1}$
}

\section{RESUMO}

Este estudo aplica técnicas de análise de decisão para a quantificação do valor econômico do Levantamento de Reconhecimento de Alta Intensidade dos Solos do Município de Sentinela do Sul, RS (escala 1:50.000), e do Levantamento de Solos da Bacia Carbonífera do Baixo Jacuí, RS (escala 1:100.000) através de informações econômicas sobre as culturas regionais e avaliação da qualidade do levantamento de solos. A estimativa do valor econômico é feita pela quantificação do aumento do rendimento econômico quando o planejamento de uso das terras considera as informações contidas no levantamento de solos. Os resultados desta avaliação evidenciam que os benefícios econômicos gerados pelo uso de informações constantes em levantamentos de solos $(R \$ 153,15$ $h a^{-1}$ e R\$70,15 $\mathrm{ha}^{-1}$, em escala 1:50.000 e 1:100.000, respectivamente) são maiores que os custos associados à execução de levantamentos de solos $\left(R \$ 1,03 \mathrm{ha}^{-1}\right.$ para um mapa na escala 1:50.000 e $R \$ 0,38 \mathrm{ha}^{-1}$ para um mapa na escala 1:100.000).

Palavras-chave: solos, levantamento de solos, mapeamento, valor econômico.

\section{ABSTRACT}

This study applies decision analysis techniques for the qualification of economic value of the a high intensity Soil Survey of Sentinela do Sul County, RS, Brazil (scale 1:50,000) and a soil survey of the Charcoal Basin of the Jacuí River, RS, Brazil (Scale 1:100,000), using economic information related to the major regional crops and soil survey quality. The determination of the economic value is made by quantifying the increase in economic return when land use planning uses soil survey information. Results of this evaluation highlight the economic benefits generated by the use of soil survey information $\left(R \$ 153,15 h a^{-1}\right.$ e $R \$ 70.15 h^{-1}$, respectivelly for a 1:50,000 map and for a 1:100,000 map) are larger that soil survey costs $\left(R \$ 1.03 \mathrm{ha}^{-1}\right.$ for a 1:50,000 map and $R \$ 0.38 \mathrm{ha}^{-1}$ for a 1:100,000 map).

Key words: soil, soil survey, mapping, economic value.

\section{INTRODUÇÃO}

O conhecimento da distribuição dos solos permite o planejamento das atividades agrícolas de forma a maximizar a produtividade das culturas e a reduzir a degradação ambiental. A falta de disponibilidade de levantamentos de solos em escala adequada em diversas regiões do Brasil traz com o consequência a má utilização dos recursos naturais, com degradação dos solos e com obtenção de rendimentos e lucros abaixo do potencial regional. Embora a comunidade científica seja consciente deste problema, normalmente iniciativas relacionadas à execução de novos levantamentos de solos dependem de decisões políticas e econômicas. Em países com escassez de recursos, os governos locais têm relutado em manter programas de levantamentos de solos, em parte porque eles não podem determinar o retorno do seu investimento nem antes e nem após os levantamentos serem realizados. O uso de informações obtidas em levantamentos de solos, juntamente com informações sobre o retorno econômico de diversas culturas, pode ser usado para testar a viabilidade econômica dos levantamentos de solos através da comparação dos

${ }^{1}$ Departamento de Solos da Faculdade de Agronomia da Universidade Federal do Rio Grande do Sul (UFRGS), Porto Alegre, RS, Brasil.

${ }^{2}$ Autor para correspondência, av. Bento Gonçalves, 7712, 91540-000, Porto Alegre, RS, Brasil. Fone: (51) 3316-7461. E-mail: giasson@ufrgs.br. 
custos associados à execução dos levantamentos de solos com os benefícios econômicos gerados pelo uso dos mesmos.

Vários pesquisadores têm desenvolvido conceitos e técnicas para o desenvolvimento de indicadores da qualidade dos levantamentos de solos e para a avaliação de benefícios e custos destes levantamentos. Um estudo pioneiro de BECKET \& BURROUGH (1971) comparou diferentes mapas de solos e quantificou seus padrões de qualidade, manifestando uma primeira preocupação científica com o tipo e utilidade das informações de solos, entretanto sem ainda quantificar aspectos econômicos. Com o mesmo intuito de valorar as informações contidas em levantamentos de solos, BIE \& BECKETT (1971) avaliaram a eficiência do uso de mapas de solos através da quantificação de sua qualidade e dos custos de produção, introduzindo o conceito relativo à possibilidade de quantificação dos benefícios do uso de levantamento de solos, efetivanto a quantificação de custos, porém somente sugerindo possíveis métodos para a quantificação econômica de seus benefícios. DENT \& YOUNG (1981) usaram um exemplo simplificado para ilustrar que os benefícios econômicos dos levantamentos de solos podem ser calculados por meio da comparação dos lucros gerados com diferentes combinações de usos da terra e unidades de mapeamento de solos. WESTERN (1978) afirmou que, se a qualidade dos levantamentos de solos pudesse ser medida através de seus benefícios econômicos, seu valor poderia ser expresso como a relação entre os custos de realização do levantamento de solos e os benefícios que ele produz, mais uma vez destacando a necessidade da quantificação dos benefícios dos mesmos.

Todos os autores citados anteriormente contribuíram para a formação de conceitos e exploração de possíveis métodos para avaliação do benefício econômico do uso de levantamentos de solos. Embora vários parâmetros tenham sido propostos para a avaliação da utilidade dos levantamentos de solos, cada um destes termos foi usado em diferentes contextos e com propósitos diferenciados. De fato, até recentemente, nenhuma metodologia vinha realmente sendo usada para a quantificação do valor econômico dos levantamentos de solos considerando seus benefícios, embora por décadas esta idéia tenha sido conceitualizada e reconhecida como necessária, apesar de WESTERN (1978) considerar “extremamente difícil quantificar-se os benefícios dos levantamentos de solo".

Um princípio adequado que poderia ser utilizado para calcular os benefícios econômicos de um levantamento de solos é a comparação da lucratividade de diferentes tipos de uso da terra ou sistemas de manejo em cada unidade de mapeamento. Para cada tipo de solo deve existir um tipo economicamente ótimo de uso da terra ou manejo do solo, sendo que esta maior lucratividade pode ser alcançada se cada unidade de mapeamento puder ser usada com este uso ótimo. Para alcançar-se isto, requerse, primeiramente, a disponibilidade de um mapa de solo e, segundo, o conhecimento do melhor uso e manejo para cada unidade de mapeamento (DENT \& YOUNG 1981)

Uma metodologia que usa informações econômicas e levantamentos de solos reais como base para a aplicação de técnicas de análise de decisão na quantificação do valor econômico dos levantamentos de solos foi proposta (GIASSON et al., 2000). Estes autores desenvolveram esta metodologia assumindo que, em um mercado aberto e competitivo, uma adequada quantificação do valor de um levantamento de solos decorre dos benefícios gerados pelo seu uso que, por sua vez, dependem da qualidade da informação contida no levantamento de solos. Assim, rendimentos econômicos são associados a combinações de tipos de uso da terra e tipos de solos. Nesta metodologia, é proposta a comparação do valor monetário esperado (rendimento líquido) quando a decisão sobre o uso da terra é feita baseada em diferentes situações de disponibilidade de informações sobre as características e distribuição espacial dos solos, ou seja, quando a decisão sobre o uso da terra é feita sem o uso de levantamentos de solos e com o uso de levantamentos de solos. O aumento no valor monetário esperado gerado pelo uso da informação dos levantamentos de solos caracteriza o valor da informação, ou o valor do benefício gerado pelo uso dos levantamento de solos.

Baseado na hipótese de que a metodologia desenvolvida por GIASSON et al. (2000) é factível de ser aplicada em situações reais avaliando-se o valor econômico de levantamentos de solos do Rio Grande do Sul e que os levantamentos de solos tem valor econômico diferenciado e superior ao seu custo de execução, este estudo tem como objetivo quantificar o valor econômico de levantamentos de solos no Município de Sentinela do Sul e na Região Carbonífera do Baixo Jacuí e comparar os mesmos com os custos associados à produção de levantamentos de solos.

\section{MATERIAL E MÉTODOS}

Os levantamentos de solos que tiveram seus valores econômicos avaliados, neste estudo, são denominados Solos da Bacia Carbonífera do Baixo Jacuí, RS e Levantamento Semidetalhado dos Solos de Sentinela do Sul, RS, respectivamente publicados por 
SCHNEIDER et al. (1996) e KLAMT et al. (1996), nas escalas 1:100.000 e 1:50.000.

O Município de Sentinela do Sul, com área de $253 \mathrm{~km}^{2}$, está inserido nos domínios de três regiões fisiográficas, identificadas como Serra do Sudeste, Encosta do Sudeste e Zona Costeira, cujo modelado geomorfológico é controlado por condicionamentos geológicos peculiares. A maior parte do território municipal está situada sobre o Escudo Cristalino (précambriano), representado por um complexo granitognáissico com migmatitos associados, e por ocorrências isoladas de granitos intrusivos mais jovens. Nestas áreas, o relevo varia de ondulado a montanhoso escarpado. Na porção sul e sudeste de Sentinela do Sul, predominam sedimentos cenozóicos da Bacia de Pelotas. Depósitos fluviais completam a sedimentação de transição entre o domínio geomorfológico dos granitóides e da sedimentação costeira. O clima é do tipo CfaII 2 c subtropical, com temperatura média anual de $18,2^{\circ} \mathrm{C}$ e precipitação média de $1.600 \mathrm{~mm}$ por ano (KLAMT et al., 1996).

A área abrangida pelo levantamento de solos da Bacia Carbonífera do Baixo Jacuí, com aproximadamente $950 \mathrm{~km}^{2}$, situa-se dentro das bacias hidrográficas do Arroio dos Ratos e do Arroio do Conde, as quais ocupam parte dos municípios de Charqueadas, São Jerônimo, Arroio dos Ratos, Butiá e Minas do Leão. Segundo PROJETO BRASIL (1986), a geologia e o relevo da área são bastante heterogêneos, o que permite compartimentá-la em quatro padrões distintos. O relevo associado a rochas graníticas varia entre fortemente ondulado a montanhoso. Sob o relevo predominantemente ondulado, ocorrem associações de rochas metamórficas e migmatíticas. Em relevo suavemente ondulado, ocorrem arenitos, associados a siltitos e a folhelhos amarelados, folhelhos carbonosos e carvão. Em conjunto, estes três compartimentos predominam, ocupando aproximadamente dois terços da área. O quarto compartimento, ocupando a área restante, apresenta relevo ondulado a suavemente ondulado, associado a uma diversidade de rochas sedimentares da Depressão Central (argilitos, siltitos e arenitos); e plano, associado a depósitos aluvionais. O clima da região onde se insere a área objeto do levantamento, pela classificação de Köppen, é do tipo Cfa 2 - subtropical úmido, com temperatura média anual de $18,0^{\circ} \mathrm{C}$ e precipitação média de $1.700 \mathrm{~mm}$ por ano (SCHNEIDER et al., 1996).

A partir das observações de ocorrência de solos no mapa (\% da área), foram calculadas as probabilidades anteriores, que são as probabilidades de ocorrência de cada unidade de mapeamento na área mapeada.
As informações sobre as principais culturas agrícolas regionais necessárias à elaboração da análise econômica foram obtidas através de levantamentos junto a EMATER/RS e de pesquisa bibliográfica (FNP Consultoria \& Agroinformativos, 2003; FECOAGRO/ RS, 2003; AFUBRA, 2005). O conjunto de informações necessárias constitui-se da identificação das principais culturas agrícolas da área de estudo e de estimativas do retorno econômico de cada uma destas culturas em combinação com cada uma das unidades de mapeamento ocorrentes nas respectivas áreas de estudo.

Estas informações, previamente coletadas, foram processadas de acordo com a metodologia proposta por Giasson et al. (2000), utilizando as técnicas de análise de decisão descritas por CLEMEN (1996), sendo que todas as informações disponíveis foram organizadas em árvores de decisão usando o programa Data 3.0 (TREEAGE, 1997). A organização das árvores de decisão permitiu mostrar a estrutura do processo de decisão em diversas situações de disponibilidade de informações sobre solos, além da quantificação do Valor Monetário Estimado (VME) de cada situação. Para tanto, para cada uma das duas áreas em estudo foram determinados os VME para duas situações: 1) uso da terra sem a existência de informações sobre o tipo e distribuição de solos nos municípios; e 2) uso da terra considerando a existência de informações perfeitas sobre o tipo e distribuição de solos nos municípios.

Na primeira situação estudada (decisão quanto ao uso da terra sem a existência de informações sobre o tipo e distribuição de solos no município), considera-se a seleção do uso da terra em função do rendimento econômico esperado para cada combinação de uso e unidade de mapeamento (UM) de solos e da probabilidade de ocorrência de cada UM de solo, que é definida a partir da porcentagem da área ocupada pelos mesmas (Tabelas 1 e 2). Ou seja, decide-se o uso independentemente da distribuição dos solos na paisagem, assumida como desconhecida, e posteriormente obtém-se um benefício econômico diferente para cada combinação de uso da terra e UM de solo, sendo a probabilidade da ocorrência desta combinação igual à porcentagem da área ocupada pela UM de solo). Estas situações de decisão são estruturadas em árvores de decisão. Nestas árvores, além das ramificações, cujo significado é escrito na sua parte superior, existem pontos de bifurcação, chamados nódulos, que apresentam simbologia com significado específico: os nódulos representados por quadrados representam situações de decisão, os nódulos representados por círculos representam situações probabilísticas, cuja probabilidade de 
Tabela 1 - Unidades de mapeamento (UM)de solos com suas respectivas classificação taxonômica atualizada, proporção da área ocupada e rendimento econômico esperado do cultivo de arroz e da sucessão fumo/milho no Município de Sentinela do Sul.

\begin{tabular}{|c|c|c|c|c|}
\hline \multirow{2}{*}{ UM } & \multirow{2}{*}{ Classes taxonômicas de solos } & \multirow{2}{*}{$\begin{array}{l}\text { \% da área } \\
\text { mapeada }\end{array}$} & \multicolumn{2}{|c|}{ Rendimento ( $\left.\mathrm{R} \$ \mathrm{ha}^{-1}\right)$} \\
\hline & & & Arroz & Fumo/Milho \\
\hline PE-PV & $\begin{array}{l}\text { GRUPO INDIFERENCIADO ARGISSOLO VERMELHO Distrófico } \\
\text { típico + ARGISSOLO VERMELHO AMARELO Alumínico típico }\end{array}$ & 19,7 & 0 & 1156 \\
\hline PV-C & $\begin{array}{l}\text { COMPLEXO DE ARGISSOLO VERMELHO AMARELO Alumínico } \\
\text { típico + CAMBISSOLO HÁPLICO Alumínico típico }\end{array}$ & 20,4 & 0 & 1098 \\
\hline PV-C-R & $\begin{array}{l}\text { COMPLEXO DE SOLOS ARGISSOLO VERMELHO AMARELO } \\
\text { Alumínico típico + CAMBISSOLO HÁPLICO Alumínico típico + } \\
\text { NEOSSOLOS REGOLÍTICOS Distróficos típicos }\end{array}$ & 24,3 & 0 & 1040 \\
\hline $\mathrm{R}$ & NEOSSOLOS REGOLÍTICOS Distróficos típicos & 3,3 & 0 & 809 \\
\hline PV-PT-PL & $\begin{array}{l}\text { ASSOCIAÇÃO DE ARGISSOLO VERMELHO AMARELO } \\
\text { Alumínico típico }+ \text { PLINTOSSOLO ARGILÚVICO Alumínico } \\
\text { abrúptico + PLANOSSOLO HÁPLICO Distrófico típico plano; }\end{array}$ & 6,8 & 635 & 1098 \\
\hline PT-PL-HGP & $\begin{array}{l}\text { ASSOCIAÇÃO DE PLINTOSSOLO ARGILÚVICO Alumínico } \\
\text { abrúptico + PLANOSSOLO HÁPLICO Distrófico típico plano + } \\
\text { GLEISSOLO HÁPLICO Tb Distrófico }\end{array}$ & 15,2 & 804 & 370 \\
\hline HGP-A & $\begin{array}{l}\text { ASSOCIAÇÃO DE GLEISSOLO HÁPLICO Tb Distrófico + } \\
\text { NEOSSOLOS FLÚVICOS }\end{array}$ & 5,1 & 846 & 0 \\
\hline $\mathrm{HGH}$ & GLEISSOLO MELÂNICO Distrófico & 6,2 & 846 & 0 \\
\hline
\end{tabular}

ocorrência é descrita na parte inferior da ramificação, e os nódulos representados por triângulos representam possíveis resultados. A situação de decisão é resolvida através da seleção do tipo de uso da terra (ramificação) com maior VME, calculado pela média dos benefícios econômicos de cada combinação de uso e UM de solo ponderada pela área de ocorrência da UM ou probabilidade anterior.

Na segunda situação, o melhor uso da terra é determinado considerando-se a disponibilidade de informações perfeitas sobre a distribuição das UM de solos nas paisagens. Assim, para Sentinela do Sul e para a Bacia Carbonífera do Baixo Jacuí, respectivamente, estrutura-se esta situação conforme as árvores de decisão, onde a seleção do melhor uso da terra é feita após o conhecimento do tipo de solo e conhecendo-se o retorno econômico de cada combinação de UM e tipo de uso da terra. Assim, para cada UM listada no levantamento de solo, selecionase o tipo de uso da terra com maior rendimento econômico líquido. Este rendimento líquido é multiplicado pela probabilidade anterior da UM (\% área ocupada pela mesma), obtendo-se o VME para a combinação. O somatório dos VME de todas as combinações é o VME que caracteriza esta situação de decisão.

A diferença entre VME com informação perfeita e o VME sem informação, denominado Valor Estimado Sem Informação (VESI), sobre solos mostra um valor máximo potencial de um levantamento de solos perfeito e é denominado Valor Esperado com Informação Perfeita (VEIP).

\section{RESULTADOS E DISCUSSÃO}

Os levantamentos de solos avaliados apresentaram-se compostos por unidades de mapeamentos (UM) simples, associações, complexos e grupos indiferenciados de solos. As áreas do Município de Sentinela do Sul e Bacia Carbonífera do Baixo Jacuí apresentam, respectivamente, oito e 16 unidades de mapeamento de solos, conforme tabelas 1 e 2 .

No Município de Sentinela do Sul, os usos da terra selecionados como representativos são o arroz irrigado e a sucessão de fumo e milho. Na Bacia Carbonífera do Baixo Jacuí, as principais atividades agrícolas são o arroz irrigado e o uso da terra com pastagem nativa para engorda de bovinos. Os rendimentos econômicos líquidos esperados em cada um desses tipos de uso da terra em cada UM são apresentados nas tabelas 1 e 2 .

As árvores de decisão nas quais estão estruturadas as duas situações de decisão para os levantamentos de solos de Sentinela do Sul e da Bacia Carbonífera do Baixo Jacuí são mostradas, respectivamente, nas figuras 1 e 2 . Considerando a primeira situação, o tipo de uso com maior VME em Sentinela do Sul foi a sucessão fumo/milho, com VME 
Tabela 2 - Unidades de mapeamento (UM) de solos com suas respectivas classificação taxonômica atualizada, proporção da área ocupada e rendimento econômico esperado do cultivo de arroz e de pastagens nativas na Região Carbonífera do Baixo Jacuí.

\begin{tabular}{|c|c|c|c|c|}
\hline \multirow{2}{*}{ UM } & \multirow{2}{*}{ Classes taxonômicas de solos } & \multirow{2}{*}{$\begin{array}{l}\text { \% da área } \\
\text { mapeada }\end{array}$} & \multicolumn{2}{|c|}{ Rendimento ( $\left.\mathrm{R} \$ \mathrm{ha}^{-1}\right)$} \\
\hline & & & Arroz & Pastagem \\
\hline PV & $\begin{array}{l}\text { ASSOCIAÇÃO ARGISSOLO VERMELHO-AMARELO Distrófico } \\
\text { câmbico + ARGISSOLO VERMELHO Distrófico latossólico + } \\
\text { NEOSSOLO REGOLÍTICO Distrófico típico }\end{array}$ & 0,7 & 0 & 130 \\
\hline PE1 & ARGISSOLO VERMELHO Distrófico latossólico & 31,1 & 0 & 122 \\
\hline PE2 & ARGISSOLO VERMELHO Eutrófico típico & 3,2 & 0 & 122 \\
\hline PE3 & ARGISSOLO VERMELHO Distrófico típico & 0,1 & 0 & 122 \\
\hline PE4 & ARGISSOLO VERMELHO Eutrófico latossólico & 0,1 & 0 & 122 \\
\hline PE5 & $\begin{array}{l}\text { ARGISSOLO VERMELHO Distrófico latossólico }+ \text { ARGISSOLO } \\
\text { VERMELHO-AMARELO Distrófico câmbico }\end{array}$ & 9,9 & 0 & 122 \\
\hline PE6 & $\begin{array}{l}\text { ASSOCIAÇÃO ARGISSOLO VERMELHO Eutrófico típico } \quad+ \\
\text { NEOSSOLO LITÓLICO Eutrófico típico }\end{array}$ & 0,1 & 0 & 122 \\
\hline PB1 & ARGISSOLO ACINZENTADO Distrófico arênico & 3,6 & 0 & 136 \\
\hline PB2 & $\begin{array}{l}\text { ARGISSOLO ACINZENTADO Distrófico arênico }+ \text { NEOSSOLO } \\
\text { LITÓLICO Eutrófico típico }\end{array}$ & 0,5 & 0 & 136 \\
\hline PT1 & PLINTOSSOLO ARGILÚVICO Alumínico típico & 1,1 & 508 & 136 \\
\hline PT2 & $\begin{array}{l}\text { ASSOCIAÇÃO PLINTOSSOLO ARGILÚVICO Alumínico típico + } \\
\text { ARGISSOLO VERMELHO Distrófico latossólico + ARGISSOLO } \\
\text { ACINZENTADO Distrófico arênico }\end{array}$ & 2,3 & 338 & 136 \\
\hline РT3 & $\begin{array}{l}\text { ASSOCIAÇÃO PLINTOSSOLO ARGILÚVICO Alumínico típico + } \\
\text { PLANOSSOLO HÁPLICO Distrófico típico + GLEISSOLO HÁPLICO } \\
\text { Tb Eutrófico + GLEISSOLO MELÂNICO Distófico típico }\end{array}$ & 21,8 & 846 & 82 \\
\hline HGP & $\begin{array}{l}\text { ASSOCIAÇÃO GLEISSOLO HÁPLICO Tb Eutrófico + GLEISSOLO } \\
\text { MELÂNICO Distófico típico + PLANOSSOLO HÁPLICO Distrófico } \\
\text { típico }\end{array}$ & 10,9 & 846 & 82 \\
\hline R1 & $\begin{array}{l}\text { ASSOCIAÇÃO NEOSSOLO REGOLÍTICO Distrófico típico + } \\
\text { AFLORAMENTOS DE ROCHA }\end{array}$ & 4,0 & 0 & 109 \\
\hline R2 & $\begin{array}{l}\text { ASSOCIAÇÃO NEOSSOLO REGOLÍTICO Distrófico típico + } \\
\text { ARGISSOLO VERMELHO-AMARELO }\end{array}$ & 4,5 & 0 & 109 \\
\hline A & $\begin{array}{l}\text { ASSOCIAÇÃO NEOSSOLOS FLÚVICOS Distóficos e Eutróficos + } \\
\text { GLEISSOLO HÁPLICO Tb Eutrófico + GLEISSOLO MELÂNICO } \\
\text { Distófico típico }\end{array}$ & 5,6 & 804 & 82 \\
\hline
\end{tabular}

de $\mathrm{R} \$ 862,00$, sendo selecionado como o uso preferencial quando não se dispõe de informações sobre a distribuição dos solos na paisagem (VME = $\mathrm{R} \$ 1156 * 0,1970+\mathrm{R} \$ 1098 * 0,2040+\mathrm{R} \$ 1040 * 0,2430+$ $\mathrm{R} \$ 809 * 0,330+\mathrm{R} \$ 1098 * 0,0608+\mathrm{R} \$ 370 * 0,1520+$ $\mathrm{R} \$ 0 * 0,0510+\mathrm{R} \$ 0 * 0,0420=\mathrm{R} \$ 862,00)$. Para a Bacia Carbonífera do Baixo Jacuí, o tipo de uso com maior VME nesta situação foi o uso da terra com arroz, com VME de R\$337,00, sendo selecionado como o uso preferencial quando não se dispõe de informações sobre a distribuição dos solos na paisagem. Estes valores de VME determinados dessa forma são denominados de Valor Esperado Sem Informação (VESI) e são usados como referencial para comparação com os valores de VME a serem determinados nas situações onde existem informações sobre solos disponíveis (Figura 2).

Considerando a segunda situação, no Município de Sentinela do Sul, o uso das terras com fumo e milho gera os maiores rendimentos quando o cultivo nas unidades de mapeamento PE-PV (R\$ 1156,00), PV-C (R \$1098,00), PV-C-R (R \$ 1040,00), R (R\$ 809,00), PV-PT-PL (R 1098,00$)$, enquanto para as unidades de mapeamento PT-PL-HG (R\$ 804,00), HGPA $(\mathrm{R} \$ 846,00)$ e HGH $(\mathrm{R} \$ 846,00)$ o uso com maior rendimento é com arroz irrigado. O VME desta situação para Sentinela do Sul, calculado pelo somatório dos VME para cada combinação, é de R\$1015,15 (VME = $\mathrm{R} \$ 1156 * 0,1970+\mathrm{R} \$ 1098 * 0,2040+\mathrm{R} \$ 1040 * 0,2430+$ $\mathrm{R} \$ 809 * 0,330+\mathrm{R} \$ 1098 * 0,0608+\mathrm{R} \$ 804 * 0,1520+$ $\mathrm{R} \$ 846 * 0,0510+\mathrm{R} \$ 846 * 0,0420=\mathrm{R} \$ 862,00)$.

Na Bacia Carbonífera do Baixo Jacuí, o uso das terras com pastagem nativa gera os maiores rendimentos quando o cultivo nas unidades de mapeamento PV (R\$130,00), PE1 (R\$ 122,00), PE2 (R\$ 122,00), PE3 (R\$ 122,00), PE4 (R\$ 122,00), PE5 (R\$ $122,00)$, PE6 (R\$ 122,00), PB1 (R\$ 136,00), PB2 (R\$ 136,00),), R1 ( $\$$ \$ 1309,00) e R2 ( $\$$ \$ 109,00), enquanto para as unidades de mapeamento PT1 (R\$ 508,00), PT2 ( R\$ 338,00), PT3 (R\$ 846,00), HGP (R\$ 846,00 e A(R\$

Ciência Rural, v.36, n.2, mar-abr, 2006. 


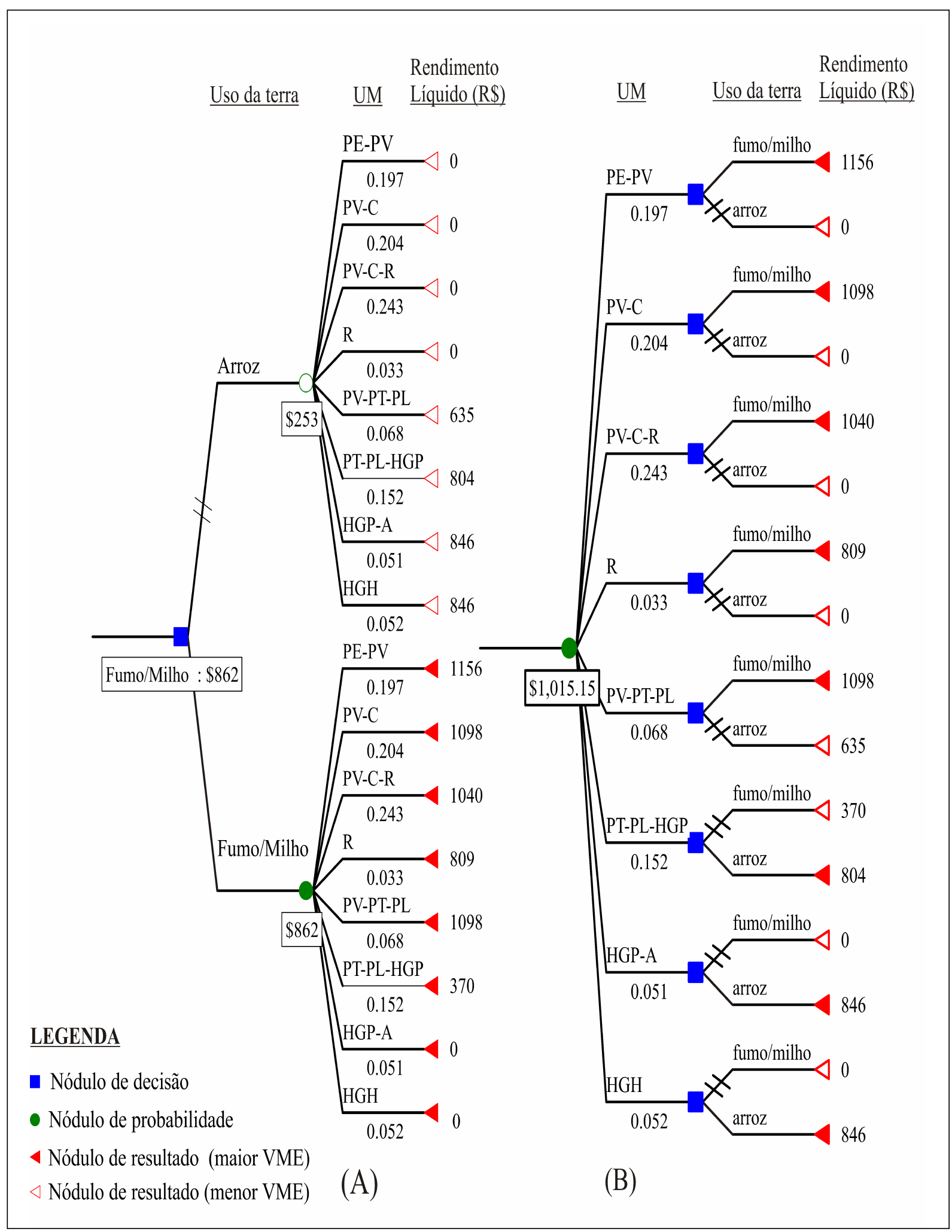

Figura 1 - Árvores de decisão para situações de decisão sobre o uso da terra (A) sem informações sobre distribuição espacial dos solos e (B) com o uso de informações perfeitas sobre distribuição espacial dos solos para do Município de Sentinela do Sul, RS. 


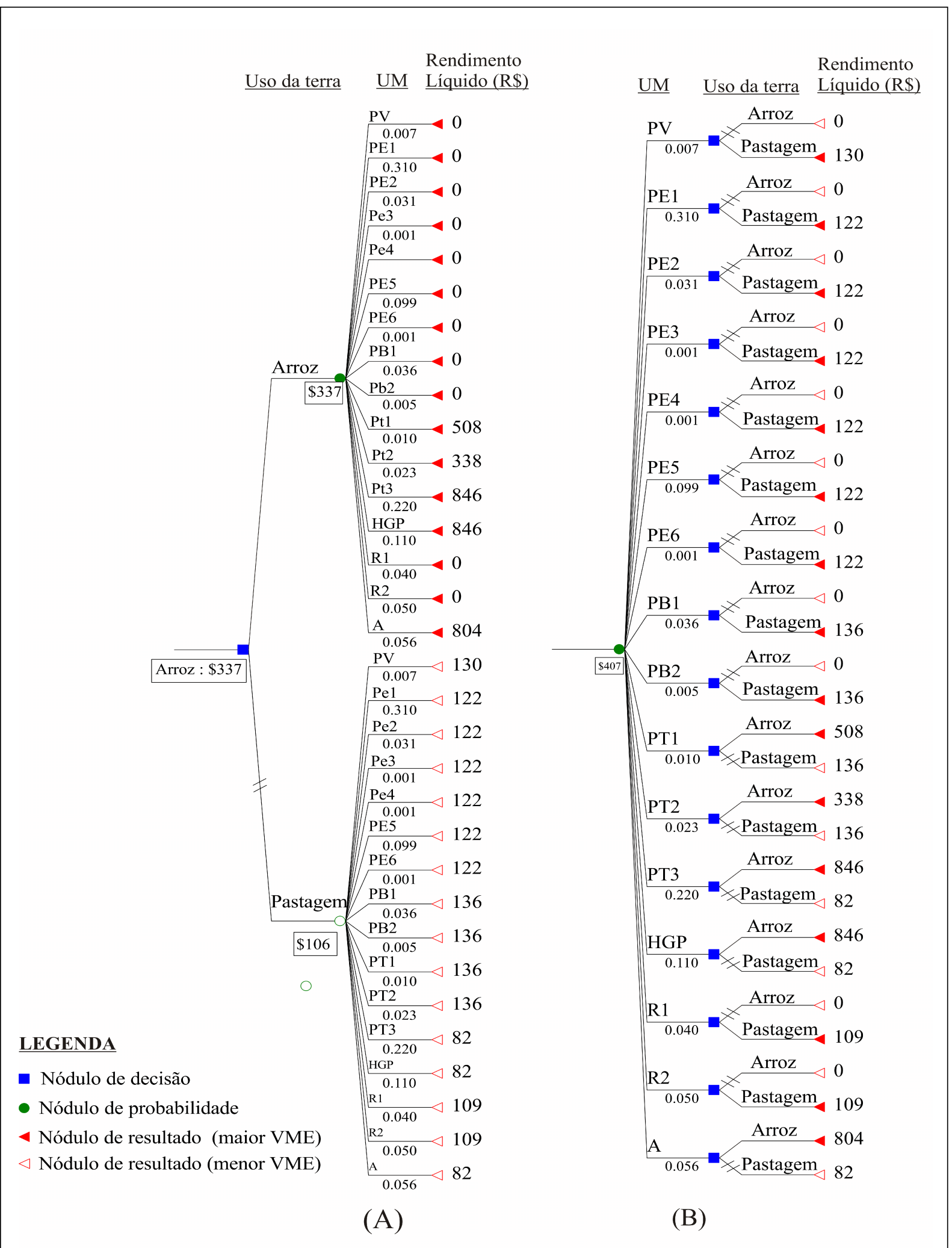

Figura 2 - Árvores de decisão para situações de decisão sobre o uso da terra (A) sem informações sobre distribuição espacial dos solos e (B) com informações perfeitas sobre a distribuição espacial dos da Região Carbonífera do Baixo Jacuí, RS.

Ciência Rural, v.36, n.2, mar-abr, 2006. 
804,00) o uso com maior rendimento é com arroz irrigado. O VME desta situação para Sentinela do Sul, calculado pelo somatório dos VME para cada combinação, é de R \$407,00.

A diferença entre este VME com informação perfeita e o VESI mostra um valor máximo potencial de um levantamento de solos perfeito e é denominado Valor Esperado com Informação Perfeita (VEIP). Neste caso, para Sentinela do Sul, o VEIP = R\$ 1015,15 - R\$ $862,00=\mathrm{R} \$ 153,15$ ha $^{-1}$ e para a Bacia Carbonífera do Baixo Jacuí VEIP = R \$ 407,00 - R \$337,00=R $\$ 70,15$ ha $^{-1}$. Destaca-se que estes valores dependem tanto da distribuição percentual das UM de solos como do rendimento econômico das culturas utilizadas nas áreas avaliadas, sendo que qualquer alteração substancial nos tipos de uso ou manejo das terras que implique alterações, no rendimento líquido das culturas implica a alteração do valor econômico do levantamento de solos. Isso demonstra que o valor econômico de um levantamento de solo não é estático e dependente somente da distribuição dos solos na paisagem, mas dinâmico e dependente do uso das terras.

$\mathrm{O}$ custo de levantamentos de solos pode ser estimado pela equação $\log C=8,16+1,4 \log S$, onde $\mathrm{C}=$ custo do levantamento de solo (em dólares por quilômetro quadrado) e $S$ é a escala do levantamento de solos (expressa na forma de fração)(BIE \& BECKET,1971). Para o levantamento de solos do município de Sentinela do Sul, na escala 1:50.000, temse um custo $C=\$ 38,14 \mathrm{~km}^{-2}$, que equivale a $\$ 0,38 \mathrm{ha}^{-1}$, ou R\$1,03ha ${ }^{-1}$. Para o levantamento de solos da Bacia Carbonífera do Baixo Jacuí, na escala 1:100.000 tem-se um custo $C=\$ 14,45 \mathrm{~km}^{-2}$, que equivale a $\$ 0,14 \mathrm{ha}^{-1} \mathrm{e} \mathrm{a}$ $\mathrm{R} \$ 0,38 \mathrm{ha}^{-1}$.

A comparação demonstra que os custos de execução de levantamentos de solos de R $\$ 1,03 h^{-1}$ e $\mathrm{R}$ \$ $0,38 \mathrm{ha}^{-1}$ são muito inferiores aos benefícios do trazidos pelo uso destes levantamento de solos ( $\mathrm{R} \$$ 153,15ha ${ }^{-1}$ e $70,15 \mathrm{ha}^{-1}$, respectivamente). Mesmo desconsiderando-se a longevidade dos levantamentos de solos, que poderiam trazer benefícios às comunidades por décadas, e só considerando-se os benefícios no primeiro ano de uso, constata-se que uma avaliação econômica não deixa dúvidas sobre a lucratividade em investimentos como o mapeamento ou levantamento de solos.

\section{CONCLUSÃO}

Os resultados mostram que a metodologia testada é adequada para calcular o valor econômico dos levantamentos de solos e evidenciam que os benefícios econômicos gerados pelo uso de informações constantes em levantamentos de solos (R\$ 153,15ha ${ }^{-1}$ e R\$ 70,15ha ${ }^{-1}$, respectivamente para o Município de Sentinela do Sul e para a Bacia Carbonífera do Baixo Jacuí) são muito maiores que os custos associados à execução de levantamentos de solos (R\$ 1,03ha ${ }^{-1}$ para um mapa na escala 1:50.000 e R\$ $0,38 \mathrm{ha}^{-1}$ para um mapa na escala $\left.1: 100.000\right)$. Essa informação serve de subsídio para demonstrar publicamente para a população em geral e para os tomadores de decisão que o investimento na execução de levantamentos de solos é completamente viável, considerando-se o aumento de rendimentos, com o aumento dos rendimentos produzidos pela adequada tomada de decisão quanto ao uso das terras já no primeiro ano de uso. Se considerar-se que a vida útil de um levantamento de solos certamente é de várias décadas, pode-se perceber a indiscutível lucratividade associada à produção de mapas e levantamentos de solos.

Deve ser considerado que os retornos econômicos estimados são apenas aqueles contabilizados diretamente com rendimentos líquidos obtidos na produção agrícola regional quando o levantamento de solos é efetivamente utilizado. Destaca-se que este valor econômico pode ser muito ampliado, no caso de considerar-se outros usos não agrícolas, como seleção de áreas para desenvolvimento urbano, locação de estradas, descarte de resíduos, etc. De outra forma, deve-se destacar que, neste estudo, para fins práticos, avaliou-se somente o potencial econômico para a seleção do melhor uso da terra. Quando selecionando o uso mais adequado para as terras, princípios de conservação do solo e do ambiente sugerem que as avaliações da aptidão agrícola das terras sejam consideradas, o que pode alterar o valor econômico do levantamento de solo, pela exclusão do processo produtivo de áreas de terra inaptas ao cultivo.

\section{AGRADECIMENTOS}

À Fundação de Amparo à Pesquisa do Estado do Rio Grande do Sul (FAPERGS), pelo financiamento integral deste estudo, através de recursos cedidos como Auxílio Recém-

Ciência Rural, v.36, n.2, mar-abr, 2006. 
Doutor. Aos colegas Edemar Valdir Streck, Renato Levien, Miguel Dall’Agnol, Carlos Nabinger e Júlio Otávio Jardim Barcelos, pela colaboração nas discussões para definição dos parâmetros econômicos usados neste estudo.

\section{REFERÊNCIAS}

AFUBRA. Acessado em: 15 de Abril de 2005. On-line. Disponível na Internet http://www.afubra.com.br/.

BECKETT, P.H.T.; BURROUGH, P.A. The relation between cost and utility in soil survey IV: comparison of utilities of soil maps produced by different survey procedures. J Soil Sci, v.22, n.4, p.466-480, 1971.

BIE, S.W.; BECKETT, P.H.T. Quality control in soil survey II: the costs of soil survey. J Soil Sci, v.22, n.4, p.453-465, 1971.

CLEMEN, R.T. Making hard decisions: an introduction to decision analysis. Duxbury: Pacific Groove, 1996. 664p.

DENT, D.; YOUNG, A. Soil survey and land evaluation. London: George Allen \& Unwin, 1981. 278p.

FECOAGRO/RS. Custos de produção. Porto Alegre. Federação das Cooperativas Agropecuárias do RS, 2003. 32p. (Estudo, 62).
FNP Consultoria \& Agroinformativos. Agrianual 2004: anuário da agricultura brasileira. São Paulo, 2003. 496p.

GIASSON, E. et al. Assessing the economic value of soil information using decision analysis techniques. Soil Science, v.165, n.12, p.971-978, 2000.

KLAMT, E. et al. Levantamento semidetalhado de solos do Município de Sentinela do Sul, RS. Porto Alegre: Departamento de Solos, UFRGS, 1996. 94p. (Relatório Técnico).

PROJETO RADAMBRASIL. Folha SH.22 Porto Alegre e parte das folhas SH.21 Uruguaiana e SI.22 Lagoa Mirim. Rio de Janeiro: IBGE, 1986. 791p. : il. + 6 mapas.

SCHNEIDER, P. et al. Solos da bacia carbonífera do Baixo Jacuí, RS. Porto Alegre: Departamento de Solos, UFRGS, 1996. 50p. (Relatório Técnico).

TREEAGE SOFTWARE INC. Data 3.0 user's manual. Williamstown: Treeage Software Incorporation. 1997. 346p.

WESTERN, S. Survey quality and survey value. In: WESTERN, S. Soil survey contracts and quality control. 1978. $284 \mathrm{f}$. Monographs (Soil Survey) - Oxford University. 